\title{
СОВРЕМЕННЫЕ ИНСТРУМЕНТЫ ФИНАНСОВОГО АНАЛИЗА В УПРАВЛЕНИИ КОМПАНИЕЙ
}

\author{
(C) 2021 Петров Александр Михайлович \\ доктор экономических наук, профессор, доцент \\ Департамент бизнес-аналитики \\ Финансовый университет при правительстве Российской Федерации, Россия, Москва \\ E-mail: ampetrov@fa.ru \\ (C) 2021 Цыпин Александр Павлович \\ кандидат экономических наук, доцент \\ Департамент бизнес-аналитики \\ Финансовый университет при правительстве Российской Федерации, Россия, Москва \\ E-mail: aptsypin@fa.ru \\ (C) 2021 Кузин Максим Алексеевич \\ студент группы ГФК19-1 \\ кафедра «Государственный финансовый контроль и казначейские дело» \\ Финансовый университет при правительстве Российской Федерации, Россия, Москва \\ E-mail: Erfe.erf2015@yandex.ru
}

Эффективное управление предприятием основывается на изучении и анализе бизнес-процессов, что делает незаменимым финансовый анализ в процессе менеджмента и формирования стратегии развития фирмы, по этой причине рассмотрение новых, креативных методов и подходов в анализе является актуальной задачей, решаемой в рамках экономической науки. Цель научной работы - теоретическое осмысление применения креативных (нестандартных) подходов для проведения финансовой аналитики для совершенствования процессов управления в компании. Для достижения поставленной цели в рамках исследования были использованы такие методы научного познания как анализ, сравнения и исторический. В качестве основных результатов исследования можно назвать следующее: увеличение информационного потока приводит к необходимости использования на предприятии современных информационно-аналитических систем, но имеющиеся на сегодняшний день решения не охватывают все бизнес-процессы и требуют значительных затрат на их внедрение; наращивание предприятиями баз данных приводит к необходимости использования новых методов и алгоритмов в финансовом анализе, в этом направлении наиболее перспективным можно считать применение искусственных нейронных сетей. Направление дальнейшего исследования видится в рассмотрении возможностей применения информационных технологий и в частности нейронных сетей в анализе реальной деятельность предприятия и формировании стратегии его дальнейшего развития.

Ключевые слова: анализ, финансовый анализ, менеджмент, статистика, анализ данных, предприятие, бизнес-процессы, нейронные сети.

\section{Введение}

В условиях рыночной экономики конкуренция - это одна из основополагающих составляющих экономической системы, она дает рынку развитие, заставляет компании вести проекты более обдуманно, планировать каждый шаг, адаптировать свои цены и технологии, а также изучать и исследовать зоны своих интересов. Развитие конкурентного преимущества позволяет компании приобрести новых клиентов, соответственно извлечь прибыль. Постоянное отслеживание трендов, особенностей, опасностей и возможностей занимаемой ниши возможно при помощи инструментов бизнесаналитики, затрагивающей множественные сферы воздействия. Ведение грамотной бизнесаналитики играет в вопросе конкурентного преимущества особую роль - позволяет быть в курсе возможных проблем и опасностей, точек роста и возможностей к развитию, а также иметь 
четкую стратегию, основанную не на интуиции управленца, а на объективных показателях. Все это делает финансовый анализ одним из ключевых инструментов управления предприятием. В этой связи считаем, что рассмотрение современных подходов к этому виду анализа является актуальной задачей.

Рассматривая теоретико-методологические подходы к экономическому анализу (в том числе и финансовому анализу) и внедрение в него новых методов, можно констатировать, что данная тема достаточно новая, ею занимались такие ученые как АстраханцеваИ.А. [1], Власенкова Т.А. [4], Каширина Е.А. [8], Киселев В.Б. [9], Косарева Ю.А. [10], Куриленок К.Л. [11], Лосева А. В. [12], Петров А. М. [14], Шнайдер В. В. [23], Юрлов В.А. [25].

В свою очередь, применение информационно-аналитических систем в анализе бизнеспроцессов нашли свое отражение в работах таких исследователей как Белова О.А. [3], Рогуленко Т. М. [15], Смагин Е. В. [17], Фокина А. О. [19]. Что касается внедрения искусственных нейронных сетей в практику финансового анализа, то можно выделить следующих авторов, разрабатывавших эту тему: Зорина Е.А. [6], Курочкина И.П. [13], Хамхоева Ф.Я. [20], Шаталина А.В. [22].

Труды вышеперечисленных авторов являются теоретической и методологической базой для выполнения настоящего исследования работы.

\section{Методы и подходы}

При проведении исследования были использованы такие методы научного познания как анализ, сравнения и исторический. Что позволило выявить новые подходы к проведению финансового анализа и разработать методику их применения к фактическим бизнес процессам.

Исследование преследовало такую цель, как теоретическое осмысление применения креативных (нестандартных) подходов для проведения финансовой аналитики для совершенствования процессов управления в компании.

Настоящее исследование основывается на классических и актуальных публикациях отечественных ученых в области теоретикометодологического обоснования применения методов, алгоритмов и подходов финансового анализа для целей эффективного управления предприятием.

\section{Результаты исследования}

Для начала стоит разобрать этимологию термина «анализ» в общем и «финансовый анализ» в частности.

Термин «анализ» является крайне неопределенным и расплывчатым в связи с тем, что он достаточно распространен и используется в разных финансовых дисциплинах (и не только в экономике, но и точных науках). В научной среде существует небольшое количество определений исследуемого термина.

Рассуждая об анализе необходимо сделать замечание о его важности в познании экономических явлений, которые воспринимаются нами как единое целое, неделимое, а иногда априорное, но не проникая в сущность его элементов, не выявив его признаки невозможно познать такие явления. Как отмечает в своей работе Суслов И.П. «при рассмотрении подобных явлений некоторые признаки незначительны, иные не существенны и лишь некоторые имеют ключевое значение в понимании и осознании сущности» [18]. Среди множества признаков исследователь должен найти основные, на которых основываются все остальные, т.е. порождающие основу явления и отражают объективные законы. Лишь посредством анализа исследование идет от единичного к всеобему, от случайного к необходимому, от непосредственно данного, эмпирически конкретного к опосредованному, мысленно абстрактному. При этом в процессе анализа части явления рассматриваются не как самостоятельные элементы, а в контексте единого целого, взаимосвязанные друг с другом.

Таким образом, под анализом в дальнейшем будем понимать процесс разложения экономического явления на взаимосвязанные элементы, с целью познания сущности этого явления и закономерностей его развития.

При рассмотрении анализа очень важно определить его предмет и объект. Так, согласно работе Ионовой А.Ф, «предмет экономического анализа - это совокупность анализируемых экономических процессов, причинно-следственных связей и методов их исследования» [7]. При этом объектами анализа являются бизнес-процессы, протекающие на предприятии (микроуровень) и в первую очередь экономические результаты хозяйственной деятельности. 
В свою очередь, «финансовый анализ» рассматривается, как производная от анализа. Он должен затрагивать более глубинные и массивные объемы данных, быть более ценной и значимой, чем анализ.

Для более глубокого понимания рассматриваемого понятия, обратимся к формулировкам известных отечественных и западных ученых, приведенные в таблице 1 .

Согласно приведенным определениям термин «финансовый анализ» обладает следующими признаками: основывается на данных бухгалтерской (налоговой) отчетности; использует ключевые индикаторы бизнес-процессов предприятий; измеряет воздействие как экзогенных, так и эндогенных факторов на деятельность предприятия; ключевыми показателями являются индикаторы эффективности деятельности предприятий; позволяет предвидеть возможные состояния предприятия в среднесрочной перспективе; субъектами являются как внешние пользователи, так и менеджеры организации; является основанием для принятия управленческих решений.

Итак, приведем авторское определение понятия «финансовый анализ», под которым будем понимать часть бизнес-аналитики, основанной на методах и показателях экономического ана- лиза, направленной на непрерывное получение информации для принятия стратегических управленческих решений, и затрагивающей все основные процессы и системы, определяющие экономическое положение компании.

Стоит отметить, что для получения большего эффекта, финансовая аналитика должна представлять собой непрерывный процесс, обеспечивающий постоянный сбор и обработку данных бизнес-процессов. Для этого компании используют различные системы сбора данных или так называемые корпоративные информационноаналитические системы, под которыми будем понимать определённую совокупность методов и решений, используемых для создания единого информационного пространства управления и обеспечения деятельности компании.

Наиболее простыми с точки зрения развертывания в информационной системе предприятия и удобства эксплуатации являются пакеты программ, направленные на финансовый анализ, по мнению Фокиной А. О. [19] Наиболее распространенными на российском рынке можно считать «Audit Expert» и «Альт Финансы». К недостаткам данных пакетов можно отнести охват лишь финансовых индикаторов и выпадение из анализа остальных направлений, к примеру, анализа внешней среды, в которой функциони-

Таблица 1. Определение термина «финансовый анализ» в научных публикациях отечественных ученых

\begin{tabular}{|c|c|}
\hline Автор(ы) & Определение \\
\hline $\begin{array}{l}\text { Ионова А. Ф., } \\
\text { Селезнева Н.Н. }\end{array}$ & $\begin{array}{l}\text { «Финансовый анализ - вид экономического анализа, который используется внешними } \\
\text { пользователями информации о деятельности организации, а также управленческим } \\
\text { персоналом компании с целью получения детальных данных, содержащихся непосред- } \\
\text { ственно в регистрах бухгалтерского учета» [7]. }\end{array}$ \\
\hline $\begin{array}{l}\text { Банк В. Р., } \\
\text { Банк С. В., } \\
\text { Тараскина А. В. }\end{array}$ & $\begin{array}{l}\text { «Финансово-экономический анализ - это анализ показателей, характеризующих } \\
\text { хозяйственную деятельность предприятия, при этом главное внимание уделяется } \\
\text { финансовым результатам деятельности предприятия н эффективности использования } \\
\text { финансовых ресурсов: выполнению финансового плана, эффективности использования } \\
\text { собственного и заемного капитала, выявлению резервов увеличения суммы прибыли, } \\
\text { росту рентабельности, улучшению финансового состояния и платежеспособности пред- } \\
\text { приятия. Им занимаются финансовая служба хозяйствующего субъекта, финансовые } \\
\text { и кредитные органы» [2] }\end{array}$ \\
\hline Ефимова О. В. & $\begin{array}{l}\text { «Финансовый анализ это процесс рассмотрения текущего и будущего финансового со- } \\
\text { стояния хозяйствующего субъекта, меняющегося под воздействием внешней и внутрен- } \\
\text { ней среды и управленческих решений, в целях оценки его финансовой устойчивости } \\
\text { и эффективности деятельности» [5] }\end{array}$ \\
\hline $\begin{array}{l}\text { Русак Н. А., } \\
\text { Русак B.A. }\end{array}$ & $\begin{array}{l}\text { «Фнансовый анализ - это исследовательский процесс, главной целью которого являет- } \\
\text { ся выработка наиболее обоснованных предположений и прогнозов изменения финанс-- } \\
\text { вых условий функционирования субъекта хозяйствования» [16] }\end{array}$ \\
\hline Хелферт Э. & $\begin{array}{l}\text { «Финансовый анализ - это и исследование, и процесс, которые помогают ответить на } \\
\text { вопросы, поставленные в процессе управления» [21] }\end{array}$ \\
\hline
\end{tabular}

Источник: составлено авторами на основе теоретико-методологических и эмпирических работ в области финансового анализа 
рует предприятие. Более развернутая классификация программ, осуществляющих финансовый анализ рассматривается в исследовании Беловой О.А. [3].

На наш взгляд, приведенные пакеты программ не соответствуют современным запросам бизнеса, так как информационный поток увеличивается и усложняется, многие предприятия формируют массивы больших данных, требующих новых подходов к их осмыслению и анализу. Они не позволяют «видеть полной картины» и формировать взвешенные управленческие решения. В этой связи, считаем, что более эффективными являются комплексные решения, охватывающие все бизнес-процессы, протекающие на предприятии.

Представленные в настоящее время информационные системы поддержки управленческих решений, такие как ERP (система планирования ресурсов предприятия), SCM (управление цепями поставок), CRM (система управления взаимоотношениями с клиентами), PLM (система управления жизненным циклом продукта), SCM (управление взаимоотношениями с поставщиками) также имеют фрагментарный характер и не позволяют оценить все бизнес-процессы. K тому же процесс развертывания данных систем сопряжен со значительными затратами капитала, человеческих ресурсов и времени.

В контексте применения специализированного программного обеспечения в анализе детальности фирмы, заслуживает внимание подход Gartner Group, которая представила концепцию системы ERP II, вобравшую в себя отслеживание таких процессов как: работа с поставщиками и подрядчиками, планирование и управление ресурсами, взаимодействие с потребителями, т.е. вбирает в себя все основные направления деятельности предприятия. Но в текущее время готовых решений в рамках указанной концепции не представлено на рынке.

Тем не менее, стоит заметить, что подобные системы призваны собирать информацию по различным отделам компании, обновлять в режиме он-лайн, выводить общие результаты. Поскольку аналитика - процессное явление, она должна проводится непрерывно. И чтобы не усложнять процесс сбора и обработки информации о бизнес-процессах, необходимо интегрировать подобные системы в информационную среду предприятия.

Стоит отметить что финансовый анализ применяется внешними пользователями информации о деятельности организации, а также управленческим персоналом компании с целью получения детальных данных, содержащихся непосредственно в регистрах бухгалтерского учета.

Вышерассмотренные термины и элементы можно изложить в форме схемы процесса управления предприятием, приведенной на рисунке 1.

Согласно приведенной схеме можно указать, что в поле зрения финансового анализа попадает несколько основных направлений: анализ внешней среды и, в частности, рынка, в рамках которого действует предприятие; риски, связанные с функционированием бизнеса; качество производимой продукции (работ, услуг);

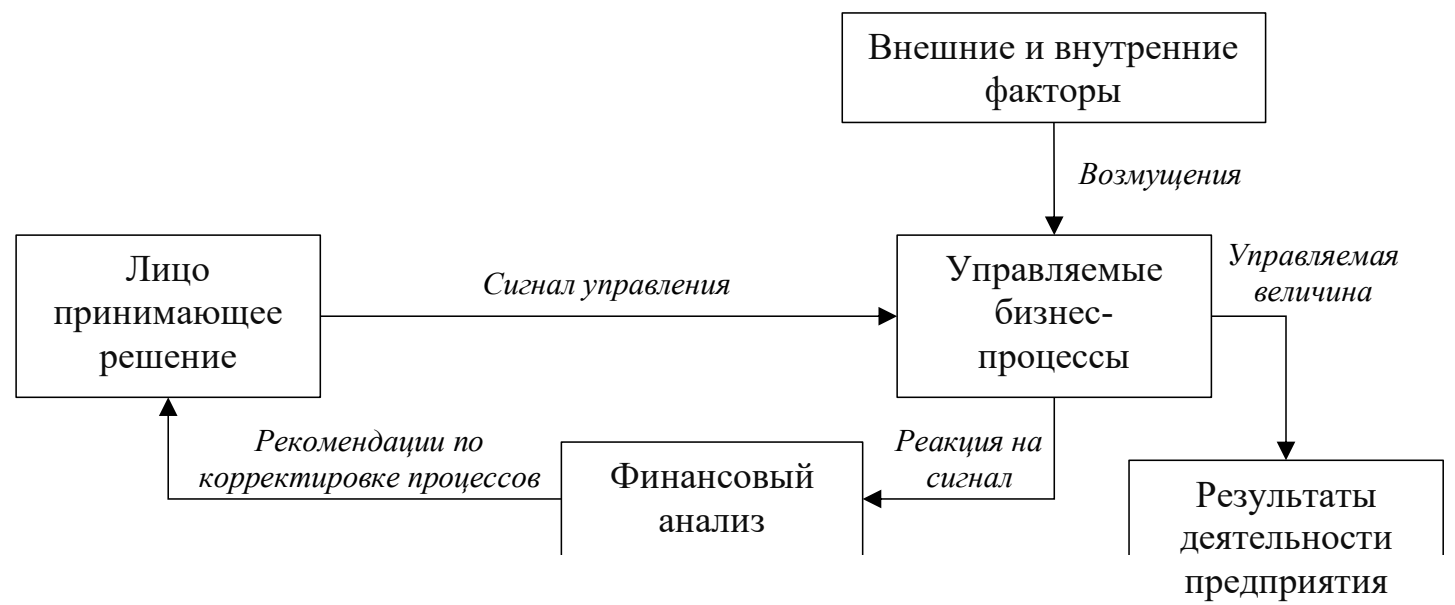

Puc. 1. Процесс управления предприятием Источник: авторская разработка 
трудовые ресурсы и их потенциал; воспроизводимый капитал, в том числе, основные фонды и финансовые активы; всестороннее изучение выпускаемой продукции (работ, услуг); индикаторы эффективности финансово-хозяйственной деятельности.

Анализ выделенных направлений позволяет установить слабые стороны системы компании, выявить резервы увеличения эффективности предприятия и построить прогнозы развития бизнеса в среднесрочной перспективе.

Классические подходы к проведению финансового анализа в разрезе рассматриваемых направлений можно представить в виде таблицы 2.

Представленные в таблице 2 методы и подходы к проведению финансового анализа и эффект от их применения к бизнес-процессам предприятий многократно описаны в отечественной и зарубежной литературе и не требуют углубленного рассмотрения. В рамках настоящего исследования более подробно остановимся на алгоритмах, которые получили толчок в развитии благодаря повсеместному распространению информационных технологий, направленных на сбор и обработку информации.

Рассмотрение новых методов, которые возможно использовать в рамках финансового анализа предприятия, целесообразно начать с рассмотрения статистического инструментария, который получил новый виток развития с появлением специализированного программного обеспечения и вылился в новое направление Data Science (наука о данных).

Значительный поток информации о бизнеспроцессах формирует базу данных к которой можно применить различные методы Data Science, и в первую очередь изучение причинноследственных связей в рамках эконометрического моделирования. Стоит отметить, что стохастический анализ активно используется в рамках комплексного анализа хозяйственной деятельности предприятия. Он позволяет увязать финансовые результаты с основными факторами производства. Но, как отмечает в своем исследовании КуриленокК.Л. и Куриленок Е., «аппарат производственных функций ... не находит применения в практике анализа хозяйственной деятельности предприятия» [11]. В частности, авторы предлагают обогатить арсенал анализа такими производственными функциями как: функция издержек; S-образная кривая П.Рида; частная функции спроса и др. Несмотря на значительные успехи в применении эконометрических методов в экономических исследованиях, они имеют ряд недостатков, связанных с оценкой параметров модели методом наименьших квадратов, в частности, это проблемы мультиколлениарности, гетероскедостичности и автокорреляции. Также в подобных моделях влияние комплекса переменных проецируется на одну зависимую переменную, что в современных условиях недостаточно, так как

Таблица 2. Классические способы финансового анализа

\begin{tabular}{|c|c|}
\hline Направления анализа & Классические методы и подходы к проведению финансового анализа \\
\hline Анализ внешней среды & $\begin{array}{l}\text { Анализ пяти сил Портера; SWOT-анализ; матрица BCG; матрица Мак- } \\
\text { кинси (модель McKinsey); матрица Артур Д. Литл (Модель АДЛ/ЛС) }\end{array}$ \\
\hline $\begin{array}{l}\text { Анализ рисков функционирования } \\
\text { предприятия }\end{array}$ & $\begin{array}{l}\text { Бизнес-план; Средневзвешенная стоимость капитала (WACC); Эконо- } \\
\text { мическая добавленная стоимость EVA; Рентабельность инвестиций ROI }\end{array}$ \\
\hline $\begin{array}{l}\text { Контроль качества продукции } \\
\text { (работ, услуг) }\end{array}$ & $\begin{array}{l}\text { Графические статистические методы (гистограмма, распределение, } \\
\text { диаграмма разброса; контрольные карты, диаграмма Исикавы); метод } \\
\text { Порето; }\end{array}$ \\
\hline $\begin{array}{l}\text { Анализ кадрового состава и потен- } \\
\text { циала работников }\end{array}$ & $\begin{array}{l}\text { Анкетирование; опрос; метод сценариев; метод «Делфи»; прогнози- } \\
\text { рование HR-затрат; метод экспертных оценок; HR-дашборд (витрина); } \\
\text { Метод «деловых игр» }\end{array}$ \\
\hline $\begin{array}{l}\text { Анализ воспроизводимого капи- } \\
\text { тала }\end{array}$ & $\begin{array}{l}\text { Классические методы экономического анализа: цепных подстановок, } \\
\text { абсолютных и относительных разниц; индексы; интегральный метод; } \\
\text { коэффициентный метод. }\end{array}$ \\
\hline $\begin{array}{l}\text { Анализ динамики, ритмичности } \\
\text { и структуры выпущенной продук- } \\
\text { ции (работ, услуг) }\end{array}$ & $\begin{array}{l}\text { Коэффициентный метод; анализ временных рядов; индексы структур- } \\
\text { ных сдвигов и различий; графический метод; индексы }\end{array}$ \\
\hline $\begin{array}{l}\text { Анализ эффективности деятельно- } \\
\text { сти предприятия }\end{array}$ & $\begin{array}{l}\text { Расчет показателей ликвидности, финансовой устойчивости и рента- } \\
\text { бельности }\end{array}$ \\
\hline
\end{tabular}

Источник: составлено авторами на основе теоретико-методологических и эмпирических работ в области финансового анализа 
деятельность предприятия оценивается с помощью группы результативных переменных [24].

Стоит заметить, что повсеместная цифровизация и накопление значительных массивов информации позволяет пойти дальше, и использовать значительную часть методов Data Science. В частности, открывается возможность решения классических статистических задач с использованием искусственных нейронных сетей. К примеру, задача прогнозирования может быть решена в таких направлениях как моделирование и предсказание объемов будущих продаж и(или) оценки влияния бизнес-процессов предприятия на финансовые результаты деятельности. В свою очередь, задача типизации и классификации может быть реализована в отношении группировки поставщиков и покупателей по уровню их надежности.

Коллектив авторов под руководством Курочкина И. П. в своем исследовании раскрывают возможности нейронной сети применительно к решению проблемы детерминированного факторного анализа [13]. Ученые приходят к выводу, что нейросети могут быть эффективны и полезны по ряду причин: во-первых, предоставляют возможность использовать латентные, косвенные и нелинейные взаимосвязи; во-вторых, существует обратная связь, позволяющая корректировать ошибки предсказания; в-третьих, реализована возможность адаптации отклонений входных переменных (факторов), которые появляются вследствие турбулентности российской экономики.

В работе Шаталина А.В. и Рогачева А.В. на основе MATLAB версии R2019b 9.6 была предложена нейронная сеть для планирования продаж в ООО «Мегаполис - Топливная группа» [22]. В ходе тестирования модели на годовых данных (в дневном разрезе) были получены прогнозы на следующий хозяйственный год, характеризующиеся незначительным расхождением с фактическими данными.

Хамхоева Ф.Я. в своем исследовании рассматривая достоинства и недостатки нейронных сетей применительно к финансовому анализу приходит к выводу, что по сравнению с распространенными статистическими методами, нейросети имеют ряд неоспоримых преимуществ, в частности, они являются гибкими и быстро адаптируются к новой информации, а также требуют сравнительно небольших познаний в математике для формулирования задачи [20].
Коллектив исследователей Зорина Е.А. и Петраковская Е.В., рассматривая возможность внедрения нейронных сетей в информационноаналитическую сеть предприятия, выделяют следующие положительные моменты [6]: во-первых, нейросети позволяют получить более точные прогнозы финансового состояния и вероятности банкротства предприятия относительно традиционных статистических методов; во-вторых, нейросети можно использовать при отсутствии явных связей между показателями; в-третьих, для использования нейросетей, аналитику не требуются специальные знания в математике и статистике. Также авторы выделяют ряд отрицательных моментов: во-первых, полученные модели не позволяют выделить (разделить) вклад каждого фактора в формирование финансовых результатов; при имеющемся уровне сложности и одновременности бизнес-процессов, модель на основе нейросети имеет ограниченные возможности учета новых событий, в противном случае это приводит к изменению спецификации нейросети, т.е. встает проблема переобучения сети.

Таким образом, искусственные нейронные сети являются одним из перспективных направлений, могут быть развернуты в информационно-аналитической системе предприятия, выдают высокоточные прогнозы и не требуют значительных затрат времени на освоение.

\section{Выводы}

В современной рыночной системе существует конкуренция среди компаний. Она отсеивает слабые компании, которые не смогли приспособиться, оставляя сильные. Чтобы остаться на рынке и быть эффективным, необходимо постоянно развивать свое конкурентное преимущество. Оно может состоять из большого числа вещей: предлагаемый ассортимент, используемые технологии, особое отношение к клиентам, общая осведомленность о рынке, конкурентах, клиентах, прочее. Чтобы иметь конкурентное преимущество, необходимо постоянно отслеживать изменения и тенденции на рынке, вносить модернизации, проводить исследования. Один из инструментов для повышения конкурентного преимущества - финансовая аналитика, представляющая из себя свод анализов, затрагивающих те сферы, которые наиболее сильно влияют на экономическое состояние компании. По необходимости, финансовая аналитика мо- 
жет содержать анализ всех сфер менеджмента организации.

В итоге, правильно настроенная информационно-аналитическая система, содержащая в себе новые подходы, методы и алгоритмы, позволяет в режиме онлайн отслеживать все возможные факторы, влияющие на финансовую систему предприятия, осуществлять прогнозирование и вырабатывать взвешенные управленческие решения. В итоге, это повышает конкурентоспособность предприятия на рынке, его возможности и перспективы, а, следовательно, и прибыль, которую эта компания будет способна извлечь из имеющихся ресурсов.

\section{Библиографический список}

1. Астраханцева И.А., Коюпченко И. Н. Финансовая аналитика и современные финансовые практики // Финансовая аналитика: проблемы и решения. - 2017. - Т. 10. - № 6 (336). - С. 701-718.

2. Банк В. Р., Банк С. В., Тараскнна А. В. Финансовый анализ. - М.: ТК Велби, Изд-во Проспект, 2006. - 344 с.

3. Белова, О.А. Программные средства финансового анализа / О.А. Белова // Вестник Чебоксарского кооперативного института. - 2009. - № 2(4). - С. 172-182.

4. Власенкова Т.А. Индикаторный метод как инструмент обеспечения финансовой безопасности хозяйствующего субъекта / Т. А. Власенкова, Т. М. Панченко, А. П. Цыпин // Известия Саратовского университета. Новая серия. Серия: Экономика. Управление. Право. - 2020. - Т. 20. - № 3. - С. 271-283. - DOI 10.18500/19942540-2020-20-3-271-283.

5. Ефимова О.В. Финансовый анализ: современный инструментарий для принятия экономических решений / О. В.Ефимова. - 5-е изд., испр. - Москва: Изд-во Омега-Л, 2014. - 348 с.

6. Зорина Е.А. Нейросетевые технологии в экономическом анализе деятельности корпораций / Е.А. Зорина, Е. В.Петраковская // Формирование рыночных отношений в Украине. - 2019. - № 10(221). - С. 7-18. - DOI 10.5281/zenodo.3564208.

7. Ионова А. Ф. Финансовый анализ / А. Ф. Ионова, Н. Н. Селезнева. - М.: Проспект, 2006. -623 с.

8. Каширина Е.А. Обзор методов финансового анализа / Е.А. Каширина // Контентус. - 2016. - № 3(44). C. $61-65$.

9. Киселев В.Б. Оценка эффективности инвестиционных проектов / В. Б. Киселев // Хранение и переработка сельхозсырья. - 1997. - № 7. - С. 33-36.

10. Косарева Ю. А. Методы финансового анализа / Ю. А. Косарева // Научный электронный журнал Меридиан. 2020. - № 3(37). - C. 564-566.

11. Куриленок К. Л. Новые методы экономического анализа / К.Л. Куриленок, Е. Куриленок // Наука и инновации. - 2019. - № 12(202). - С. 61-66.

12. Лосева А. В. Анализ степени регионального неравенства по налоговым показателям / А.В. Лосева // Региональная экономика: теория и практика. -2009 . - № 31. - С. 66-72.

13. Метод нейронных сетей в моделировании финансовых показателей компании / И. П. Курочкина, И. И. Калинин, Л.А.Маматова, Е.Б.Шувалова // Статистика и Экономика. - 2017. - № 5. - С. 33-41. - DOI 10.21686/2500-3925-2017-5-33-41.

14. Петров А. М. Учет и анализ: учебник / А. М.Петров, Е. В.Басалаева, Л.А. Мельникова; А. М. Петров, Е. В.Басалаева, Л. А. Мельникова. - Москва: КУРС, 2012. - 510 с.

15. Рогуленко, Т.М.Использование в управлении корпоративной учетно-контрольной системы / Т. М. Рогуленко, А. В. Бодяко // Вестник университета. - 2019. - № 11. - С. 29-35. - DOI 10.26425/1816-4277-2019-1129-35.

16. Русак В.А., Русак Н.А. Финансовый анализ субъектов хозяйствования: справ. пособие. - Минск: Высшая школа, 1997. - 309 с.

17. Смагин Е.В. Информационно-технологическая поддержка принятия управленческих решений на основе аналитических методов / Е. В. Смагин // Научные Записки ОрелГИЭТ. - 2020. - № 4(36). - С. 104-107.

18. Суслов И.П. Методология экономического исследования: общие вопросы. - Москва: Мысль, 1974. - 334 с.

19. Фокина А.О. Исследование программных продуктов, применяемых при анализе финансового состояния предприятия / А. О. Фокина, А. Ю. Гурьянова // Инновации и инвестиции. - 2017. - № 6. - С. 138-143.

20. Хамхоева Ф.Я. Нейронные сети в экономическом анализе: плюсы и минусы / Ф. Я.Хамхоева // Norwegian Journal of Development of the International Science. - 2020. - № 51-4. - C. 72-75.

21. Хелферт Э. Техника финансового анализа: путь к созданию стоимости бизнеса: [Пер. с англ.] / Э. Хелферт. -10-е изд. - СПб.: Питер: Питер бук, 2003. - 637 с. 
22. Шаталина А.В. Использование нейронных сетей в экономическом анализе / А. В.Шаталина, А. В. Рогачева // Математическое и компьютерное моделирование в экономике, страховании и управлении рисками. 2019. - № 4. - С. 105-109.

23. Шнайдер B. В. SWOT-анализ и его значение при формировании экономической диагностики субъекта хозяйствования / В.В.Шнайдер // Гуманитарные балканские исследования. - 2021. - Т. 5. - № 1(11). - С. 4143.

24. Эконометрика: лабораторный практикум / В. Л. Сомов, М. Н. Толмачев, А. П. Цыпин [и др.]. - Саратов: Саратовский социально-экономический институт (филиал) федерального государственного бюджетного образовательного учреждения высшего образования «Российский экономический университет им. Г.В.Плеханова», 2019. - 97 с.

25. Юрлов В.А. Анализ финансовых результатов деятельности предприятия: теория и методология / В.А. Юрлов, А. Д. Бурыкин // Экономика и управление: проблемы, решения. - 2018. - Т. 1. - № 5. - С. $102-110$. 